\title{
Nicknames of Female Felons
}

\author{
Barbara H. Zaitzow \\ Appalachian State University \\ †James K. Skipper, Jr. \\ and \\ Claudia Bryant
}

\begin{abstract}
An investigation of nicknaming among 113 female prisoners showed that nearly two-thirds of the women had a nickname. The nicknames were almost always accorded by family or peer group members, referred to physical or behavioral characteristics or were variations of given names, and were rarely negative. These findings differ sharply from earlier reports of nicknames of male criminals and male inmates. Several explanations for the findings are offered.
\end{abstract}

\section{Introduction}

At least since the time of H.L. Mencken (1919, 329-352), it has been assumed that nicknames express our sense of the significance of names and also that they exert a powerful influence on behavior (Dexter 1949, 155-157; Harré 1980, 84). However, until the 1980s, the systematic study of nicknames attracted little attention. This is one of a series of studies which attempts to expand our knowledge of the importance of nicknames in their social context.

As Leslie and Skipper (1990) observe, names are more than arbitrary symbols. They provide meanings which guide activity in social interaction and they transmit cultural knowledge. For example, they may communicate gender, ethnicity, social status or social prestige. Skipper (1989) noted that nicknames are especially important in these regards because they provide richer and more explicit denotations than do given names. Nicknames may provide miniature character sketches or illustrate aspects of a person's physical appearance, personality, or geographic origin. They also may serve as capsule histories highlighting critical incidents in people's lives.

Names 45.2 (June 1997):83-99

ISSN:0027-7738

(1)1997 by The American Name Society 


\section{Names 45.2 (June 1997)}

\section{Alternate Names}

Distinctions need to be drawn among aliases, nicknames and monickers. Aliases are temporary names adopted to conceal identity but meant to pass as legitimate names. Some are names of actual people and some are simply made up, but all appear to be genuine names. Aliases are often changed. Check forgers, for example, may use several aliases in the course of their activities.

Nicknames generally take the form of cute significations, intended either as signs of endearment or derogation. Nicknames are used mainly when their owners are young, though they may persist into later life, and some people (e.g., athletes and musicians) acquire nicknames in adulthood. There is no general agreement on what constitutes a nickname (cf. Lawson 1973; Van Buren 1974; Morgan, O'Neill, and Harré 1979). To take only one point of dispute, it is arguable whether short forms of actual names (e.g., Shoe from Shoemaker) qualify as nicknames.

Monickers are special kinds of nicknames used in criminal subcultures and are usually unknown outside of the underworld and its fringes. A monicker has an internal, subjective effect on its bearer and an external, public effect on comrades. Monickers may reflect a criminal's personal characteristics (e.g., physical, behavioral, ethnic), criminal specialty (e.g., method of operation, crime specialty), or prison-specific trait (e.g., position in the inmate hierarchy, relationships with other inmates and/or guards).

For purposes of this investigation, we define a nickname as a name given in addition to a person's legally given name(s); thus, non-criminal nicknames as well as criminal nicknames (monickers) are included. Accepted short forms of first names (Sue, Cath, Pat) and "ee" derivatives of first names (Susie, Cathy, Patty) are considered as nicknames.

\section{Frequency of Male and Female Nicknames}

Existing evidence (though fragmentary) suggests that nicknames are more common among men than women. Busse $(1983,302)$ in a study of a high school class, reported that $55 \%$ of the boys and $40 \%$ of the girls had nicknames. Skipper $(1985,100 ; 1986,53)$ found that among notorious American criminals, deviants and jazz musicians, a lower percentage of women than men were nicknamed. In a study of blues singers, Skipper and Leslie $(1988 ; 1989)$ came to the same conclusion. They suggested two reasons for the lower frequency of nicknames among 
women: women have not participated or had as much success in those occupations likely to attract nicknames, and men have had the power to be the prime nicknamers and generally are more likely to nickname other men. Support for this explanation is given by Wilson and Skipper (1990) who found, in a study of professional women baseball players (a situation in which women were the prime nicknamers) that as high a percentage of women baseball players had nicknames as men major league baseball players. It is clear, however, that in general and for whatever reasons, men more often than women are nicknamed.

\section{Sources of Male and Female Nicknames}

Phillips (1990) found that when females are nicknamed, the nicknames are most often based on physical attributes such as beauty, or personality characteristics such as pleasantness or kindness. Male nicknames, on the other hand, are more likely to be based on given names. Females were also found to be significantly more likely than males to receive nicknames from older siblings, fathers or sweethearts.

\section{Female Nickname Research}

Later research has extended Phillips' finding that females are most often evaluated on the basis of physical and behavioral characteristics. Rosenbaum and Chesney-Lind (1994) reported that the pattern noted by Phillips (1990) is found within society generally and is not limited to those having close relationships with the nicknamed. In their analysis of intake procedures for female criminals (an institutional classification process required for all newly admitted juvenile and adult offenders), they found that in cases where male personnel processed female offenders, comments on the physical characteristics of females were made in $63 \%$ of the cases. The likelihood increased if the offenders had been arrested on a "morals" charge. References to physical appearance were least likely to occur when the offenders had been arrested for a serious violation. No references were made to attractiveness by female intake personnel.

Examination of naming practices within the Citizens Band radio community further demonstrates that self-assigned "handles" (nicknames) connote gender images. While men project a clear signal of their masculine identity, females are less likely to focus on physical characteristics or sex appeal (Kalcik 1985). The ambiguity of female handles with regard to such gender marking may reflect changing female roles 


\section{Names 45.2 (June 1997)}

in contemporary America and, in particular, the entry of substantial numbers of females into the previously male-dominated world of $\mathrm{CB}$ radio. Trends reported in sex-role literature related to language (e.g., Lakoff 1975) include the pattern that men project via their handles a distinctive image of male gender characteristics. The dynamics of this situation are summarized by Lakoff (1975), who points out (in a discussion of expletives) that

men's language [or, in this instance, masculine semantics] is increasingly being used by women, but women's language is not being adopted by men.... This is analogous to the fact that men's jobs are being sought by women, but few men are rushing to become housewives or secretaries. The language of the favored group, the group that holds power, along with its nonlinguistic behavior, is generally adopted by the other group, not vice versa. (10)

\section{Nicknames in Prison and Among Criminals}

While we know little about the nicknames of female criminals, the literature indicates that nicknames are used extensively with male criminals. Nicknames are used by male criminals so frequently that law enforcement officers collect and record them in the criminals' files, and the mass media frequently refer to criminals by their nicknames (Maurer and Futrell 1982). The use of nicknames in prison and among criminals serves at least two purposes. First, it provides identity and often replaces a criminal's given name. Maurer and Futrell (1982) write:

The criminal monicker is anchored deep in the criminal psyche and becomes perhaps the most permanent possession of an individual who lives in an insecure and ever-changing world. It often helps him maintain his identity and live up to its implications. It bolsters his ego and constantly reminds him that he has a reputation in his criminal subculture.... (248)

Second, being tagged with a nickname is a sign of status. It indicates that one has made it in the criminal subculture. It is a symbol of recognition. As such, criminal nicknames are often highly connotative and the stories behind them sometimes reveal a great deal about the individuals with the nicknames. In fact, nicknames for male criminals may be used more frequently among inmates than among those who are not incarcerated. Inmate nicknames are part of the prison subculture. Jackson $(1967,50)$ remarks: "Inmate nicknames are used all the time and one not infrequently encounters men whose free world names are unknown to the prison population...." Some (e.g., Jackson [1967]; 
Maurer and Futrell [1982]) warn that if people are required to spend time in prison either as inmates or as staff members, in addition to learning the nomenclature and jargon of the environment, in order to function adequately they must acquaint themselves with the nicknames of inmates and the meanings of these nicknames. Here, too, nicknames provide identity and accord status.

Nicknames also serve an important function in building solidarity and in serving as symbols of group solidarity among those who are confined in prison. Harré (1980) has suggested that nicknames are prevalent in closed circles of friendship, secret societies, and other tightly-knit groups. One of the functions of nicknames is to demonstrate the separate and exclusive nature of the group. Through their knowledge and use of nicknames, individuals demonstrate to themselves and to outsiders their membership in or association with the group.

Skipper (1986) noted that the safety of coal miners-individually and collectively-depends on a high degree of cooperation and solidarity. Miners are in constant danger from external forces which threaten their very lives. The extensive use of nicknames among miners reflects their being members of an exclusive group. While they wear their nicknames as badges of distinction, the miners' nicknames are situation and group specific; they are never used on the surface or by non-miners. Skipper concludes that the greater the need for solidarity in a group (e.g., to counter the threat of external forces), the greater the use of nicknames.

Prison subculture, with its own established norms and codes, provides an environment conducive to the use of nicknames. The administration is an external threat. As Jackson (1967) points out, inside prison an inmate's actions are evaluated and interpreted along but a single axis from the values imposed by the administration to those expressed by the prisoners. The use of nicknames among prisoners may be an attempt by inmates to show acceptance of other inmates as well as an attempt to show prison staff that they cannot control every aspect of the prisoners' lives behind bars.

Given the paucity of research on female inmate nicknames (and indeed on female criminality in general), we assume that the following hypotheses, which are based on research of male criminal nicknames, will be true for incarcerated female felons as well; that is, in the female society of a woman's prison: 
Hypothesis 1: A greater proportion of women inmates with nicknames will report that they received their nickname from a fellow inmate than will report that they received their nickname from outside prison sources;

Hypothesis 2: A greater proportion of women inmates with nicknames will report that the nickname confers special status or identity within the prison setting than will report that the nickname does not;

Hypothesis 3: A greater proportion of women inmates will report that nickname usage is important in prison than will report that it is not.

Method

The nicknames of the female prisoners were gathered through a questionnaire distributed to 113 voluntary participants at three midwestern state correctional facilities housing a total of 980 women. This method produced a convenience sample of $11.5 \%$ of the total prison population of these three institutions. Most of the women were relatively young (mean $=32$ years); $44 \%$ had not graduated from high school, and $55 \%$ were unemployed. Eighty-two percent of the women stated that they had children to support while only $7 \%$ were married. These figures are consistent with those of the profile of women offenders provided by nationwide inquiries (Watterson 1996, 35).

A questionnaire was designed to elicit the widest possible range of nicknames and information about them. Respondents were asked whether or not they had a nickname; if they did, what it was; who was responsible for giving it; was it given before or after incarceration; who called them by their nickname; if they like being called by their nickname; and if they thought it was important that inmates have nicknames.

The 68 nicknames collected were then divided into categories. Open-ended nickname responses were independently coded by two individuals. The method by which the nicknames were classified was basically inductive. The nicknames themselves and the situational factors relating to their origin and meaning suggested categories. A rough estimate of inter-rater reliability of sorting decisions was computed in an effort to insure the integrity of the categorizations. Of the possible 
678 observations or survey items that required coding, there were only 30 items in which a coding discrepancy between raters occurred. The resulting 648 agreements were then divided by the sum of the disagreements plus the agreements; thus providing a rough agreement index. There was $96 \%$ agreement between the raters.

\section{Results}

Sources of Women Inmates' Nicknames

Sixty-eight of the 113 inmate respondents $(60 \%)$ reported nicknames. (A complete list of the nicknames, by category, is given in the Appendix.) Z-tests of differences between correlated proportions were computed for each of the three hypotheses. This statistical procedure provides a probability estimate of whether the observed proportions are significantly different (Guilford and Fruchter 1978). A summary of the nicknames is given in table 1 , which shows that 26 of the 68 nicknamed women (38\%) had been assigned their nicknames by family members and $23(34 \%)$ by friends. Only $14(21 \%)$ of the nicknames came from the prison setting. In 13 cases the nickname was given by another inmate and in one case by a correctional officer. Five respondents nicknamed themselves before incarceration. Contrary to our expectation, most women inmates received their nicknames from family members and friends residing outside the prison setting $(\mathrm{z}=-4.851, \mathrm{p}<.01)$. Hypothesis 1 was therefore rejected.

\section{Feelings About Nicknames}

While a majority of the women ( $71 \%$ ) liked their nickname (and had received it before entering prison), $22 \%$ of the women who also liked their nickname had received the nickname during incarceration. Only seven of the women (10\%), indicated they did not like their nickname, all of these being women who received their nickname before entering prison. Over one-third (34\%) of the respondents stated that their nickname was not used in prison, but only by family and/or friends. While $25 \%$ of the women stated that only prison inmates and staff referred to them by their nickname, $38 \%$ indicated that their nicknames were used both in and out of prison. 


\section{Names 45.2 (June 1997)}

Table 1. Descriptive Summary of Nicknames $(n=68)$

\begin{tabular}{|c|c|c|c|c|c|}
\hline Source of Nickname: & $\mathbf{N}$ & $\%$ & Reaction to Nickname: & $\mathbf{N}$ & $\%$ \\
\hline Physical Characteristic & 19 & 28 & Like & 48 & 71 \\
\hline Behavorial Characteristic & 16 & 24 & Not Like & 07 & 10 \\
\hline Play on Given Name & 21 & 31 & Doesn't Matter & 12 & 18 \\
\hline After Another Person & 02 & 03 & Missing & 01 & 01 \\
\hline Other & 06 & 09 & & & \\
\hline \multirow[t]{2}{*}{ Unknown } & 04 & 06 & Nickname Users: & $\mathrm{N}$ & $\%$ \\
\hline & & & Family Members & 09 & 13 \\
\hline Nickname Givers: & $\mathbf{N}$ & $\%$ & Friends & 07 & 10 \\
\hline Family Members & 26 & 38 & Inmates & 14 & 21 \\
\hline Friends & 23 & 34 & Prison Staff & 01 & 01 \\
\hline Inmates & 13 & 19 & Everyone Inside Prison & 02 & 03 \\
\hline Prison Staff & 01 & 01 & Everyone Outside Prison & 07 & 10 \\
\hline \multirow[t]{2}{*}{ Self } & 05 & 07 & $\begin{array}{l}\text { Everyone Inside \& Out- } \\
\text { side Prison }\end{array}$ & 26 . & 38 \\
\hline & & & No One Now & 01 & 01 \\
\hline Importance of Nickname: & $\mathbf{N}$ & $\%$ & Missing & 01 & 01 \\
\hline Important & 10 & 15 & & & \\
\hline Not Important & 42 & 62 & When Nickname Given: & $\mathbf{N}$ & $\%$ \\
\hline Doesn't Matter & 13 & 19 & Before Entering Prison & 52 & 76 \\
\hline \multirow[t]{2}{*}{ Missing } & 03 & 04 & During Incarceration & 15 & 22 \\
\hline & & & Before or During Stay & 01 & 01 \\
\hline
\end{tabular}

Physical Characteristics Nicknames

Table 2 shows inmate nicknames by nicknamer relationship and nickname category. Physical characteristics accounted for $28 \%$ of the nicknames and family members were the most frequent nicknamers in this category. Body size and hair color attracted most of the nicknames. There were two Tinys and two Shortys, but also a Muggie, a Pebbles, a Little One and a Flaca which, according to the respondents, also referred to short stature. One inmate was called Big Mack because she was tall and heavy and another Slim Goodie because she was tall and thin. Three Reds, a Strawberry and a Goldie reflected hair color. Baby Girl brought attention to facial features while Hour Glass Ass was a nickname other inmates gave to a woman with an oddly-shaped body. 


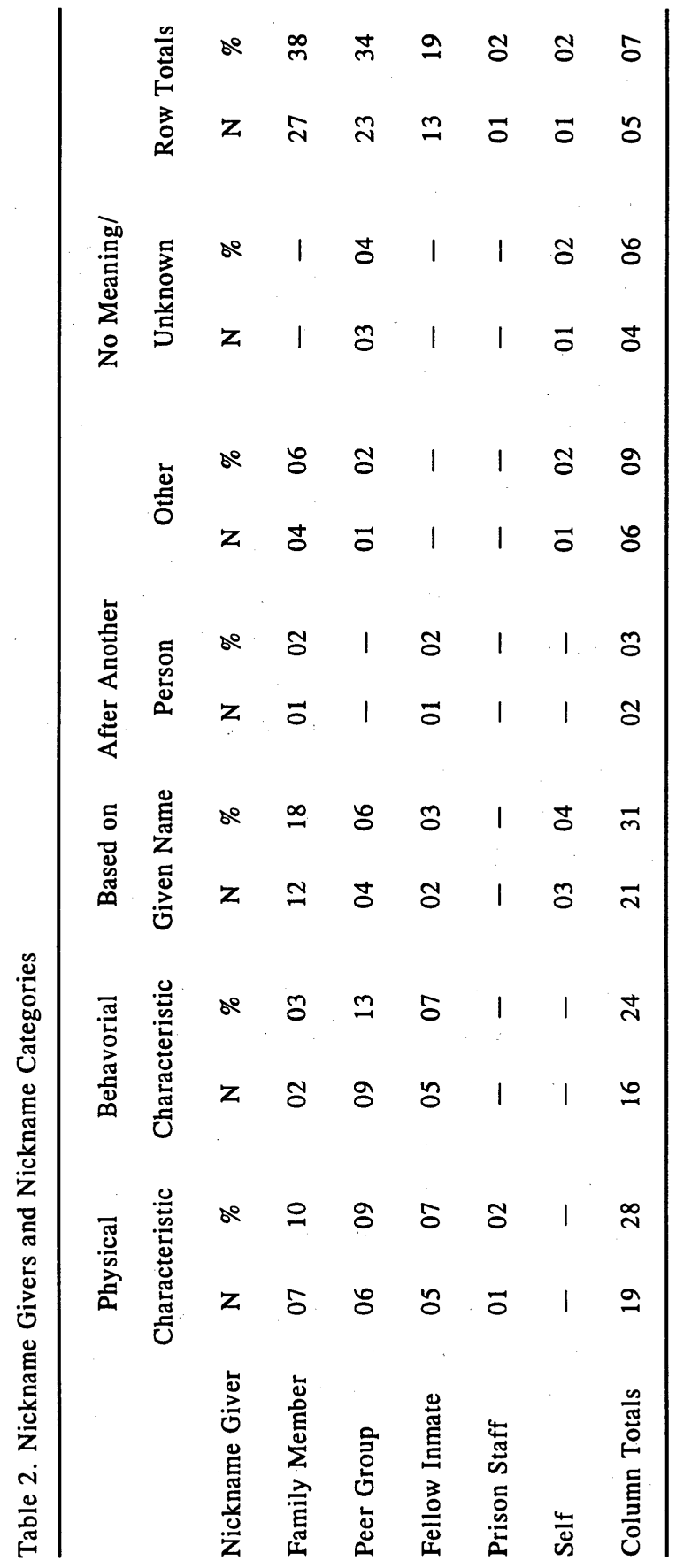




\section{Names 45.2 (June 1997)}

Behavioral Characteristics Nicknames

Almost $24 \%$ of the nicknames fell into the behavioral characteristic category and were used most commonly among fellow inmates. Nicknames in this category showed more variation and greater imagination than those relating to physical characteristics. Several nicknames were derived from the social context in which the nickname was given (as well as from supplemental information provided by the respondents). The origin of three nicknames had lesbian sexual connotations: Earvin "because I play around with women." This woman's promiscuous reputation within the prison, in combination with the timely disclosure by the famous basketball player, Magic Johnson, about his HIV status and his endorsement of monogamous relationships, resulted in her receiving this nickname; Sunshine "because my woman says I am always smiling;" and Boobie "because I have affection for my lover." In all three cases inmates were the nicknamers. One nickname's origin called attention to why the woman was incarcerated: Fly Girl "I was always flying off from one bar to another selling drugs." Disposition was the source of several nicknames, including Sugar and Precious. Most of the other nicknames appeared to be idiosyncratic: Maniac "I do crazy things;" Sam "due to my being a Tom Boy;" Mush "because I loved to kiss everyone as a child;" Chicken "when I was afraid of so many things;" Butterfly "refers to my elusiveness;" Sexy Sadie "comes from friends thinking I was sexy;" Mickey "was the name of my mother's cat I liked to play with;" Blood Poison "refers to the fact that I am hard to get out once I get in your blood;" Beamer "referred to the love of cars;" and Rocker "referred to my love of rock and roll music."

\section{Abbreviated Version of Given Name Nicknames}

Twenty-one nicknames (31\%) were based on given names. I.I. originated from the fact that a niece could not pronounce the first name. $J . J$. are the initials of the individual's first and last names while $D . J$. are the initials of the inmate's first and middle names. Dubaby is a modified version of the respondent's last name. Kitty Kat stands for Cathy, and Ree Ree for Rose Marie. Sinbad was a variation of the offender's given name but she added, "It is just a game my lover and I play to recognize each other as individuals." 


\section{Named After Other People Nicknames}

Two individuals were nicknamed after fictional people. One woman was nicknamed Lucky after the character in the book of that name by Jackie Collins and $L u L u$ referred to the cartoon character of that name.

\section{"Other" Nicknames}

These names did not fit into any of the other categories. Angela Jones or Joyce Anderson were alias names-not nicknames-used by the respondent when conducting drug deals with bar patrons. Pumpkin referred to country origins and Chief to Indian ancestry. In each of these cases, it was not clear whether the respondents were suggesting that their nicknames were physical or behavioral in nature. Finally, the origin of Baby Cakes could not be determined from the respondent's answer.

In order to test hypothesis 2, the "Physical" through "Other" nickname categories were merged to form the "Special Status/Identity" category which was tested against the "No Meaning on Origin" category. A z-test showed that this relationship was statistically significant and was in the hypothesized direction $(\mathrm{z}=6.181, \mathrm{p}<.01)$;

women inmates reported that their nicknames did confer a special status or identity. However, this identity was context-specific; the special status associated with the nickname on the outside was not relevant to status within the prison setting. Therefore, hypothesis 2 was rejected.

\section{No Meaning Nicknames}

This category was reserved for nicknames for which a meaning was not provided by the respondent. Of the four women who stated that there was no meaning attached to their nicknames, Nonnie, Laddanna and Goggie were family nicknames for which the respondents did not provide a meaning. One respondent nicknamed herself $D e b$ simply because she liked the name.

\section{Importance of Nicknames for Incarcerated Women}

All respondents were asked, "Is it important for inmates to have a nickname?" Sixteen respondents who did not have nicknames replied to this question as well as the 68 who did. Fourteen of the non-nickname respondents indicated they did not believe it was important for inmates to have a nickname and two stated it did not matter. Of the women with nicknames, $15 \%$ said it was important, $62 \%$ said it was not important, 
and the remaining $19 \%$ said it did not matter. While statistically significant $(\mathrm{z}=-4.438, \mathrm{p}<.01)$, the finding was in the direction opposite to that hypothesized; most women inmates responded that it is not important for women inmates to have a nickname while in prison. Hypothesis 3 was thus rejected.

\section{Discussion}

The notion which prompted this research-that the nicknaming process of incarcerated females would be similar to that of male prisoners-was not borne out. Based on the available nickname literature, we had hypothesized that in an all-female society such as that in a women's prison, women would be the nicknamers and they would nickname each other to a greater extent than women are nicknamed in the general population. These hypotheses were not supported. The nicknames of the female inmates in this study were almost always given by family or peer group members, referred to physical or behavioral characteristics or were variations of the nicknamed's given name, and were rarely negative. Regardless of on which side of the bars women reside, they are still largely judged on beauty or attitude, not by their deeds. In addition, over one-third of the nicknames appear to be either group or age specific since 26 of the women did not use their childhood nickname or the nickname given in "free" society while in prison. Particularly for those women who do not like their nicknames, it may be a case of not wanting to volunteer information about themselves which could be used by others in the institution to antagonize them. Not sharing one's "free world" nickname may be a way for these women to maintain their separation from other inmates and their separation from prison culture. In this respect, not using one's nickname may represent a woman offender's attempt to exercise some semblance of control over her life in an environment that promotes dependency.

The second hypothesis, that the nicknames of women offenders would confer special status or identity for those named, also was not supported. Only one of the nicknames in our data (Fly Girl) could be directly traced to criminal activity but that nickname was not used during the incarceration period. Contrary to our expectations, only $22 \%$ of the respondents acquired their nicknames during incarceration. These women were not famous career criminals whose nicknames represented symbols of honor. Instead, the situation-specific nature of their 
criminality relegated them to the more accurate status of the "not so rich and not so famous."

Finally, when asked: "Is it important for inmates to have nicknames?" $62 \%$ of the respondents with nicknames did not think it was important to have a nickname in prison. As one inmate put it, "I don't want to be a nickname; I want to be a person." It may be that, unlike men in prison, women inmates maintain their identity by not using a nickname and by attempting to divorce themselves from the crimes they committed rather than by using (and being proud of) the nicknames associated with criminal activities.

A study of this nature lends itself to a number of preliminary observations and should prompt further research in the area. We have just begun to explore some of the implications. For example, in general, nicknames of female felons do reflect societal attitudes toward women. The importance of physical attributes is revealed in the granting of more names based on these qualities. Connotations of beauty, pleasantness, kindness, and goodness are reflected in other names. Nicknaming studies may well provide fertile ground for future research on the relationship between language and culture.

Further, a female model of nicknaming practices is needed in order to provide a more complete understanding of human behavior. Sex role differences within American society make the male model inappropriate for studying female nicknaming practices. Just as Flexner (1975, xii) found "that most American slang is created and used by males," so it seems that males also control much of American nicknaming. This situation may well be connected to Morgan et al.'s $(1979,17)$ observation that whoever the namegiver may be, namegiving is a role of power.

\author{
Appendix \\ Nickname Listing \\ (Comments in Quotations were Supplied by the Women Inmates)
}

Physical Characteristics Nicknames $(\mathrm{n}=19)$

Babygirl: "Because I'm so old and look like a baby."

Big Mack: "Cuz of body size."

Flaca: "Because I'm always in a small size and don't gain weight."

Goldie: "My eyes and hair color."

Hour Glass Ass: "For the shape of my body." 


\section{Names 45.2 (June 1997)}

Lil One: "Because I'm short."

Lione: "Because I'm fine."

Little One: "Because of my size."

Muggie: "When I was young I was very short and chubby."

Pebbles: "Small."

Red: "Because it's my favorite color and because I'm light skinned."

Red: "Hair color and light skin."

Red: "Because the color I am."

Shorty: "Stature."

Shorty: "My size."

Slim Goodie: "I' $m$ in the Gangster Disciple Nation and they gave me the name when I was 12 years old."

Strawberry: "Because of my hair color."

Tiny: "My size."

Tiny: "Because I was once little."

Behavioral Characteristics Nicknames $(\mathrm{n}=16)$

Beamer: "Because I like the cars."

Blood Poison: "Once I get in the blood it's hard to get me out."

Boobie: "My girlfriend called me this, I guess same as lover or stud."

Butterfly: "I'm very elusive."

Chicken: "I was afraid to do a lot of things as a teenager."

Earvin: "Cause I was a player with the women."

Fly Girl: "Because I use to fly from one bar to another to sell my drugs."

Maniac: "Outgoing person, always ready for fun."

Mickey: "My Mom had a cat-whenever she called the cat I answered."

Mush: "I loved to kiss everyone as a child to give them dimples."

Precious: "Being compassionate, patient, sharing, and caring."

Rocker: "I love rock 'n roll."

Sam: "Had this nickname since I was 12 because I wanted to play baseball with the boys."

Sexy Sadie: "Friends called me sexy-eventually became Sexy Sadie"

Sugar: "Because I'm so sweet."

Sunshine: "Because I always smile."

Derived from Given Name $(\mathrm{n}=21)$

Bernie: "Shortened version of Bernadette."

Cathy: "Short for Catherine." 
Cindy: "Short version of Cynthia."

Debbie: "I started it because there are too many Debras."

Dee: "Short for Delores."

Di: "Shorter version of Diane."

Die: "Short for Dionne."

D J: "The first initials in my first and middle name."

Dubaby: "My last name is Dube, so I guess since the word baby is so common."

I I: "My niece couldn't say Iris when she was small."

Jerrie: "That's short for Geraldine."

J J: "Short for Janet Jean."

Kitty Kat: "Because my name is Cathy so that's where the cat comes from."

Kitty or Cat: "Cat because my name is Cathy-Kitty in reference to Cat."

Marty: "A derivative of Martha."

Mel: "It's just a shorter version of my name."

Niecey: "Short for Denise."

Ree Ree: "My youngest sister couldn't say all of Rosemarie."

Ro or Chelle: "Shorter version of my name."

Shari: "Short for Sharon."

Sinbad: "Bad Cindy."

After Another Person Nicknames $(\mathrm{n}=2)$

Lucky: "Comes from Jackie Collins book-my woman said I had mob qualities." Lulu: "Cartoon person."

"Other Nicknames" ( $\mathrm{n}=6)$

Angela Jones or Joyce Anderson: "Because I sold drugs and didn't want no one that didn't know me to know my name."

Baby Cakes: "My lover gave it to me."

Chief: "Because I've got Indian blood in me."

Lady: "My ex-boyfriend gave me the name when we first got together."

Peach: "Use to work at Pizza Hut but my cousin could only say Peachy Hut."

Pumpkin: "Because I'm a country gal."

Undetermined Origin $(\mathrm{n}=4)$

Deb: "None."

Goggie: "I walked at 6 months."

Laddanna: "I don't know-I guess it's just a speak of languages."

Nonnie: "Childhood name." 


\section{References}

Busse, Thomas. 1983. "Nickname Usage in an American High School." Names 31: 300-306.

Dexter, Emily S. 1949. "Three Items Related to Personality: Popularity, Nicknames, and Homesickness." Journal of Social Psychology 30: 155-158.

Flexner, S. 1975. "Preface." Dictionary of American Slang. Ed. H. Wentworth and S. Flexner. New York: Thomas Y. Crowell.

Guilford, J.P. and B. Fruchter. 1978. Fundamental Statistics in Psychology and Education (6th ed.). New York: McGraw-Hill.

Harré, Rom. 1980. "What's in a Nickname?." Psychology Today Jan.: 78-84.

Jackson, Bruce. 1967. "Prison Nicknames.” Western Folklore 26: 4854.

Kalcik, Susan J. 1985. "Women's Handles and the Performance of Identity in the CB Community." Women's Folklore, Women's Culture. Ed. Rosan A. Jordan and Susan J. Kalcik. Philadelphia: U of Pennsylvania P.

Lakoff, R. 1975. Language and Woman's Place. New York: Harper \& Row.

Lawson, Edwin. 1973. "Men's First Names, Nicknames and Short Names: A Semantic Differential Analysis." Names 21: 22-27.

Leslie, Paul L. and James K. Skipper. 1990. "Toward a Theory of Nicknames: A Case for Socio-Onomastics." Names 38: 273-282.

Maurer, David W. and Allan W. Futrell. 1982. "Criminal Monickers." American Speech 57: 243-255.

Mencken, H.L. 1919. The American Language: A Preliminary Inquiry Into the Development of English in The United States. New York: A.A. Knopf.

Morgan Jane, Christopher O'Neill, and Rom Harré. 1979. Nicknames:

Their Origins and Social Consequences. Boston: Routledge and Kegan Paul.

Phillips, Betty S. 1990. "Nicknames and Sex Role Stereotypes." Sex Roles 23: 281-287.

Rosenbaum, Jill Leslie and Meda Chesney-Lind. 1994. "Appearance and Delinquency: A Research Note." Crime and Delinquency 40: 250261. 
Skipper, James K. 1985. "Nicknames of Notorious American TwentiethCentury Deviants: The Decline of The Folk Hero Syndrome." Deviant Behavior 6: 99-114. . 1986. "Nicknames, Coal Miners and Group Solidarity." Names 34: $134-145$.

. 1989. "Public Nicknames of Famous Football Players and Coaches: A Socio-Historical Analysis and Comparison." Sociological Spectrum 9: 103-123.

Skipper, James K. and Paul L. Leslie. 1988. "Women, Nicknames and Blues Singers." Names 36: 193-202.

. 1988. "Nicknames \& Blues Singers Part 1: Frequency of Use 1890-1977." Popular Music and Society 12: 37-48.

. 1989. "Nicknames and Blues Singers 1890-1977, Part II: Classification and Analysis." Popular Music and Society 13: 29-43. Van Buren, Henry. 1974. "The American Way With Names." Topics in Cultural Learning, Vol. 2. Ed. R. W. Brislin. Honolulu: East-West Center, Hawaii U.

Watterson, Kathryn. 1996. Women in Prison: Inside the Concrete Womb. Boston: Northeastern UP.

Wilson, Brenda S. and James K. Skipper. 1990. "Nicknames and Women Professional Baseball Players." Names 38: 305-322. 